\title{
PRÁTICAS DE HIGIENE E A QUALIDADE DO LEITE: UMA ANÁLISE A PARTIR DA TÉCNICA DE CLUSTERS
}

\author{
Ferenc Istvan Bánkuti ${ }^{1}$ \\ Jocasta Carraro ${ }^{2}$ \\ Marcel Moreira de Brito 3 \\ Magali Soares dos Santos Pozza ${ }^{4}$ \\ Geraldo Tadeu dos Santos 5
}

BÁNKUTI, F. I.; CARRARO, J.; BRITO, M. M. de; POZZA, M. S. dos S.; SANTOS, G. T. dos. Práticas de higiene e a qualidade do leite: uma análise a partir da técnica de clusters. Arq. Ciênc. Vet. Zool. UNIPAR, Umuarama, v. 19, n. 1, p. 17-21, jan./mar. 2016

RESUMO: O objetivo proposto neste artigo foi demonstrar a viabilidade do uso da técnica de formação de clusters hierárquicos para analisar a relação entre as práticas de manejo e higiene de ordenha e suas implicações para a qualidade do leite. Foi desenvolvida pesquisa a campo e realizada coleta de dados referente a qualidade do leite de produtores da Região de Mococa, SP. A partir dessas, 455 casos foram submetidos à análise de cluster hierárquico. Dois grupos foram definidos, o primeiro, (grupo 1) caracterizado por produtores com baixa aplicação de práticas de manejo e higiene de ordenha e o segundo (grupo 2), por produtores com elevada aplicação dessas práticas. Entre os grupos, foi aplicado teste de hipóteses para comparação de diferenças percentuais entre as variáveis de manejo e higiene de ordenha. Em etapa subsequente foi feita análise descritiva e de verificação de igualdade entre os grupos, segundo variáveis de qualidade do leite. A técnica de formação de clusters hierárquicos mostrou-se adequada para análise da relação entre práticas de manejo e higiene de ordenha. Produtores rurais que adotam com maior frequência tais práticas, obtém leite de melhor qualidade.

PALAVRAS-CHAVE: Aglomerados. Análise multivariada. Sistema agroindustrial.

\section{HYGIENE PRACTICES AND MILK QUALITY: AN ANALYSIS FROM THE CLUSTER TECHNIQUE}

\begin{abstract}
The aim of this paper was to demonstrate the feasibility of using the hierarchical clusters technique to analyze the relationship between management practices and milking hygiene and the implications on milk quality. A field research was developed and carried out to collect data regarding the quality of milk produced in a dairy cooperative located in Mococa, SP. From these, 455 cases were submitted to the hierarchical cluster analysis. Two groups were defined, the first one (group 1) contained producers with low application management practices and milking hygiene, while the second one (group 2) of producers with high application of these practices. The hypothesis test was applied between the groups to compare the percentage differences between management variables and hygienic milking. Subsequently, a descriptive analysis was performed and the equality between groups was checked against milk quality variables. The hierarchical cluster formation technique was adequate for analyzing the relationship between management practices and milking hygiene. Farmers who more often adopt these practices provide better quality milk.
\end{abstract}

KEYWORDS: Agribusiness system. Clusters. Multivariate analysis.

\section{PRÁCTICAS DE HIGIENE Y LA CALIDAD DE LA LECHE: UN ANÁLISIS DESDE LA TÉCNICA DE CLUSTERS}

RESUMEN: El objetivo propuesto en este artículo ha sido demostrar la viabilidad de uso de la técnica de formación de clusters jerárquicos, para analizar la relación entre las prácticas de manejo e higiene de ordeña, y sus implicaciones para la calidad de la leche. Se ha desarrollado investigación de campo y recogidos datos referente la calidad de la leche de productores de la Región de Mococa, SP. Así, 455 casos han sido sometidos a análisis de cluster jerárquico. Dos grupos fueron definidos, el primero (grupo 1) caracterizado por productores con baja aplicación de prácticas de manejo e higiene de ordeña, el segundo grupo (grupo 2), por productores con elevada aplicación de esas prácticas. Entre los grupos, se ha utilizado prueba de hipótesis para comparación de diferencias porcentuales entre las variables de manejo e higiene de ordeña. En la próxima etapa se ha hecho análisis descriptiva y de verificación de igualdad entre los grupos, según variables de calidad de la leche. La técnica de formación de clusters jerárquicos se ha mostrado adecuada para análisis de relación entre prácticas de manejo e higiene de ordeña. Productores rurales que adoptan con mayor frecuencia tales prácticas, obtienen mejor calidad de la leche.

PALABRAS CLAVE: Aglomerados. Análisis multivariada. Sistema agroindustrial.

DOI: https://doi.org/10.25110/arqvet.v19i1.2016.5786

${ }^{1}$ Professor Adjunto do Departamento de Zootecnia da Universidade Estadual de Maringá

${ }^{2}$ Mestranda em Zootecnia pela Universidade Estadual de Maringá.

${ }^{3}$ Zootecnista e Mestre em Zootecnia pela Universidade Estadual de Maringá, Doutorando em Zootecnia pela mesma Universidade. Professor Assistente do

Centro de Ciências Agrárias da Universidade Estadual do Oeste do Paraná

${ }^{4}$ Professora Adjunta do Departamento de Zootecnia da Universidade Estadual de Maringá.

${ }^{5}$ Professor Adjunto do Departamento de Zootecnia da Universidade Estadual de Maringá. 


\section{Introdução}

O Sistema Agroindustrial (SAI) do leite apresenta importante função econômica e social para o país. O Brasil está entre os quatro maiores produtores de leite de vaca no mundo (Food and Agriculture Organization of The United Nations - FAO, 2014). Em 2012, a produção nacional foi de 31,5 bilhões de litros de leite,com quase 20 milhões de vacas ordenhadas (United States Departament of Agriculture - USDA, 2013), gerando Valor Bruto da Produção (VBP) de R\$ 30 bilhões (Confederação Nacional da Agricultura CNA, 2013).Entretanto, apesar da representatividade deste sistema, ainda há entraves ao seu desenvolvimento, entre esses, aquele relativo à qualidade da matéria-prima. De acordo com Vallin et al. (2009); Silva et al. (2011); Nero, Viçosa e Pereira (2009) e Yamasi et al. (2010), o leite produzido no Brasil é de baixa qualidade, uma vez que apresenta elevado grau de contaminação. A baixa qualidade do leite acarreta problemas de ordem econômica, tecnológica e social. Frente a essas questões, tem sido crescente as ações de governos e indústriaspara que haja melhor qualidade na produção deste produto. A qualidade do leite tem sido avaliada principalmente, a partir da Contagem de Células Somáticas (CCS) e Contagem Bacteriana Total (CBT). Da parte institucional, governo, houve definição de valores máximos desses parâmetros por meio da Instrução Normativa 62 (IN 62/MAPA/2011) ${ }^{1}$; já por parte da indústria, tais parâmetros são utilizados para cumprimento da lei e como forma de bonificação do preço a ser pago para o produtor rural. Adicionalmente, algumas indústrias têm gerado incentivos financeiros para produtores que entregam leite com maior percentual de gordura, proteína e lactose.

A qualidade do leite é influenciada por um conjunto de fatores, entre os quais: deficiências no manejo e higiene da ordenha, problemas na desinfecção de equipamentos, elevados índices de mastite, tipo de ordenha, práticas de pré-dipping e pós-dipping entre outros (LANGONI et al. 2011; SILVA et al., 2011; CITADIN et al., 2009; VALLIN et al., 2009; YAMAZI et al., 2010).

Diante do exposto, o objetivo foi demonstrar a viabilidade do uso da técnica de formação de cluster hierárquicos para analisar a relação entre as práticas de manejo e higiene de ordenha e suas implicações para a qualidade do leite.

\section{Material e Métodos}

Foi desenvolvida pesquisa a campo e realizada coleta mensal, durante o período de 13 meses, de dados sobre a qualidade do leite, entregue pela totalidade, ou seja, 35 produtores rurais , de uma Cooperativa de Produtores da Região de Mococa, SP. Para a pesquisa a campo, dois instrumentos foram utilizados: (i) a aplicação de questionário semiestruturado, formado por variáveis relativas às práticas de manejo $\mathrm{e}$ higiene de ordenha e (ii) verificação in loco do processo de ordenha nos 35 Sistemas Produtivos Leiteiros (SPL's). Com essas informações e aquelas relativas à qualidade do leite, foi

${ }^{1}$ A IN 62 estabelece os seguintes níveis mínimos para o leite: (a) lactose: $11,4 \%$; (b) proteína: $2,9 \%$ e (c) gordura: 3,0\% e níveis máximos de: (a) CCS: 600.000 Células/ml de leite e (b) CBT: 600.000 Unidades Formadoras de Colônia/ml de leite. Entre outros. (BRASIL 2011). formado banco de dados com 455 casos (13 amostras em 35 SPL's). Para esses, foi realizada análise de estatística descritiva, a fim de caracterizá-los conjuntamente.

Para as variáveis de manejo e higiene de ordenha ${ }^{2}$ foi aplicada uma das técnicas de análise multivariada, a análise de clusters hierárquicos. Essa análise resulta na formação de grupos distintos entre si, mas com grande semelhança interna entre os casos que formam cada um dos grupos (FÁVERO et al., 2009). Com os grupos formados , foi aplicado teste de hipóteses $(\mathrm{P}<0,05)$ para comparação de diferenças percentuais, entre as variáveis de manejo e ordenha que os formaram. Para tanto, utilizou-se como procedimento estatístico, a formação de tabelas cruzadas (crosstabs).

Em etapa seguinte foi feita análise descritiva e análise de verificação de igualdade entre médias (ANOVA)para os grupos formados frente às variáveis de qualidade do leite. Entre essas, valores de Contagem de Células Somáticas (CCS); Contagem Bacteriana Total (CBT); porcentagem de proteína; porcentagem de gordura e porcentagem de lactose (PEDRICO et al., 2009). As análises foram feitas no software SPSS - Stastistical Package for Social Sciences - versão 18.0 .

\section{Resultados e Discussão}

Os dados demonstraram haver grande heterogeneidade entre os Sistemas Produtivos Leiteiros analisados. Estes possuíam em média, 151,8 hectares, dos quais $27 \%$ eram destinados à produção de leite. Nestes, foram produzidos em média, 539,9 litros de leite por dia, a partir de 42 vacas em lactação.

A análise de cluster, realizada a partir das variáveis de manejo e higiene de ordenha, gerou dois grupos distintos. O primeiro formado por 390 casos (Grupo 1) e o segundo por 65 casos (Grupo 2). Esse resultado é apresentado na Tabela 1.

Tabela 1: Formação dos grupos, a partir de variáveis de manejo e higiene de ordenha,realizadas em 35 SPL durante em período de 13 meses

\begin{tabular}{c|c|c}
\hline Grupos & Casos (N) & Porcentual (\%) \\
\hline Grupo 1 & 390 & 85,7 \\
\hline Grupo 2 & 65 & 14,3 \\
\hline Total & $\mathbf{4 5 5}$ & $\mathbf{1 0 0}$ \\
\hline
\end{tabular}

Em análise seguinte, foi realizado teste de hipóteses para verificação de igualdade entre os grupos, frente às variáveis de manejo e higiene de ordenha. Os dados apresentados na Tabela 2 demonstram que os grupos são distintos $(\mathrm{P}<0,05)$. O Grupo 2 foi caracterizado como aquele que realiza, percentualmente, o maior número destas práticas.

Para o Grupo 2 a limpeza dos tetos foi feita em $80 \%$ dos casos; ao passo que para o Grupo 1, essa prática foi realizada em apenas 30\% dos casos analisados (Tabela 2). Silva et al. (2011), em pesquisa sobre a qualidade do leite, verificaram que boas práticas de manejo e higiene de ordenha tem

\footnotetext{
${ }^{2}$ As variáveis de higiene e práticas de ordenha que formaram os grupos foram: (a) Limpeza dos tetos antes da ordenha; (b) Realização de Prédipping; (c) Realização de Pós-dipping; (d) Secagem dos tetos e (e) Teste de mastite.
} 
sido pouco adotadas nos sistemas produtivos leiteiros brasileiros. Citadin et al. (2009) e Yamazi et al. (2010), também constataram inadequação nas práticas de manejo e higiene de ordenha para a totalidade dos casos analisados. Para esses autores, tais práticas são fundamentais para a redução da contaminação do leite por micro-organismos . Além disso, contribuem sobremaneira para melhor higiene do produto final, interferindo assim, na qualidade e segurança do leite e seus derivados.

Os resultados da realização de pré-dipping indicaram que no Grupo 2 essa prática foi realizada para a totalidade dos casos, enquanto que no Grupo 1 foi empregada em $46,7 \%$ dos casos analisados. Para a prática do pós-dipping, foi constatado que o Grupo 2 a realizou em $80 \%$ dos casos, tendo sido esta realizada em somente $26,7 \%$ no outro Grupo (Tabela 2). A realização das práticas de pré-dipping e pós-dipping são medidas de prevenção para a mastite ambiental que exercem influência direta na qualidade do leite. De acordo com Fonseca e Santos (2011), o pré-dipping reduz em até $50 \%$ a taxa de novas infecções. Figueredo et al. (2012) constataram que em apenas $20 \%$ das propriedades avaliadas ocorria a desinfecção dos tetos antes da ordenha. Já a desinfecção pós-ordenha era realizada em somente $10 \%$, enquanto $85 \%$ não a faziam e em $5 \%$ era realizada esporadicamente.

Para a variável secagem dos tetos, verificou-se que no Grupo 2 essa prática foi realizada em $80 \%$ dos casos e no Grupo 1,em 33,3\% dos casos analisados (Tabela 2). Santos et al. (2006) atribuem a secagem dos tetos como prática fundamental para a qualidade do leite por reduzir o risco de mastite contagiosa, além de assegurar, em grande parte, a não ocorrência de deslizamento de teteiras, uma das causas de novas infecções intramamárias.

Elmoslemany et al. (2010) também observaram que as rotinas antes da ordenha são importantes para redução da contagem bacteriana do leite, especialmente o pré-dipping e a secagem dos tetos.

Já para a realização do teste de mastite, este foi empregado na totalidade de casos para o Grupo 2, e em nenhum dos casos no Grupo 1(Tabela 2). Nero, Viçosa e Pereira (2009) também observaram a não realização do CMT na maioria (41-68,3\%) das propriedades avaliadas. A partir dos resultados das práticas de higiene e qualidade do leite empregadas pelos Grupos, fica demonstrado a maior adequação do Grupo 2 frente ao Grupo 1.

Tabela 2: Comparação percentual da utilização de práticas de manejo e higiene de ordenha entre os grupos analisados

\begin{tabular}{c|c|c}
\hline \multirow{2}{*}{ Variáveis } & $\begin{array}{c}\text { Porcentagem de práticas de manejo e } \\
\text { higiene de ordenha realizadas }\end{array}$ \\
\cline { 2 - 3 } & Grupo 1 & Grupo 2 \\
\hline Limpeza de tetos & $30,0^{\mathrm{a}}$ & $80,0^{\mathrm{b}}$ \\
\hline Pré-dipping & $46,7^{\mathrm{a}}$ & $100,0^{\mathrm{b}}$ \\
\hline Pós-dipping & $26,7_{\mathrm{a}}$ & $80,0^{\mathrm{b}}$ \\
\hline $\begin{array}{c}\text { Secagem dos } \\
\text { tetos }\end{array}$ & $33,3^{\mathrm{a}}$ & $80,0^{\mathrm{b}}$ \\
\hline Teste de mastite & $0,0^{\mathrm{a}}$ & $100,0^{\mathrm{b}}$
\end{tabular}

Letras distintas nas linhas representam diferenças estatísticas entre as médias $(\mathrm{P}<0,05)$.
Na Tabela 3, são apresentados os dados comparativos entre o Grupo 1 e Grupo 2 e as variáveis relacionadas à qualidade do leite. Os resultados demonstraram que estatisticamente $(\mathrm{P}<0,05)$, os grupos se diferenciam segundo parâmetros de CBT e de porcentagem de lactose.

De acordo com Citadin et al. (2009) e Vallin et al. (2009), a Contagem Bacteriana Total está diretamente relacionada às práticas de higiene no momento da ordenha. $\mathrm{A}$ ausência de práticas adequadas elevam os valores de CBT, reduzindo a qualidade do leite. Resultados de CBT inferiores a 20.000 UFC / $\mathrm{mL}$ refletem boas práticas de higiene (RIBEIRO NETO et al. 2012). De acordo com os parâmetros previstos pela IN62/2011/MAPA, os valores máximos previstos para a CBT são de $600.000 \mathrm{UFC} / \mathrm{mL}$ de leite. Dessa forma, somente o Grupo 2 atendeu a esse requisito.

Os teores de lactose analisados entre os grupos, indicaram maior valor $(\mathrm{P}<0,05)$ para o Grupo 2 (Tabela 3 ). Entretanto, ambos apresentaram valores inferiores àqueles preconizados pela IN62/2011/MAPA que é de 8,4\%. Para Machado, Pereira e Sarríes (2000), os teores de lactose são influenciados pela CCS do leite. Para Santos et al. (2006), a mastite determina redução contínua na concentração de lactose no leite. Por ser o componente do leite com maior capacidade osmótica, a diminuição da lactose resulta na redução da produção de leite (CUNHA et al., 2008). Adicionalmente, a lactose está relacionada aos produtos em que o rendimento depende do teor de sólidos totais no leite, o que pode levar à queda no rendimento industrial e qualidade dos produtos lácteos (VIOTTO; CUNHA, 2006).

Para as variáveis, CCS, porcentagem de proteína e porcentagem de gordura, não foi constatada diferença estatística $(\mathrm{P}>0,05)$ entre os grupos analisados (Tabela 3$)$. De acordo com Lima et al. (2006), a relação entre CCS e gordura no leite tem sido muito discutida. Os autores consideram que apesar de vários trabalhos (LIMA et al., 2006) afirmarem que valores de CCS acima de 500 mil células/mL resultam em diminuição significativa do teor de gordura no leite; essa relação foi contrária aquela resultante de suas análises; não havendo, portanto, relação clara e definitiva para esses parâmetros. Segundo Langoni (2011), os valores de CCS representam importante indicativo de perdas quantitativas e qualitativas do leite, sendo esta uma relação direta.

Os valores de CCS identificados entre os Grupos foram superiores àqueles preconizados pela IN62/2011/MAPA (600 mil células/mL de leite). Portanto, mesmo existindo para o Grupo 2 melhores práticas de manejo e higiene de ordenha, essas não influenciaram de maneira significativa na CCS. Acredita-se, que se tais práticas fossem incrementadas, os resultados poderiam ser distintos, uma vez que há relação direta entre o número de bactérias presentes nos tetos e a taxa de infecções intramamárias (SANTOS et al., 2006).

A contagem de células somáticas é influenciada por vários fatores, como idade do animal, época do ano, manejo e nutrição (CUNHA et al., 2008). Machado, Pereira e Sarríes (2000), verificaram que elevados valores de CCS causam redução nos teores de proteína e lactose; importante ressaltar que valores de proteína e gordura do leite são indicativos para a composição do valor pago ao produtor e que, portanto, maiores porcentagens desses componentes podem significar melhores preços aos produtores rurais. Entre os grupos analisados, ambos apresentaram valores de proteína e gordura 
que atendem aos requisitos mínimos propostos pela IN62/ MAPA $/ 2011$, sendo estes respectivamente de $2,9 \%$ e $3,0 \%$. Esses resultados corroboram com aqueles apresentados por Bueno et al. (2009) que constataram correlação positiva entre os valores de CBT e de proteína no leite. Para González, Durr e Fontanelli (2001) os teores de gordura no leite são influenciados principalmente pelo padrão genético do animais e pela dieta ofertada, ao passo que os teores de proteína são mais impactados pelo padrão genético .

Tabela 3: Teste de médias para variáveis de qualidade do leite, CCS, CBT, proteína, gordura e lactose, entre os grupos

\begin{tabular}{l|c|c}
\hline \multirow{2}{*}{\multicolumn{2}{c|}{ Variáveis }} & \multicolumn{2}{c}{ Média } \\
\cline { 2 - 3 } & Grupo 1 & Grupo 2 \\
\hline CCS $(1.000$ células/mL) & $672,74^{\mathrm{a}}$ & $642,66^{\mathrm{a}}$ \\
\hline CBT $(1.000 U F C * / \mathrm{mL})$ & $705,73^{\mathrm{a}}$ & $139,28^{\mathrm{b}}$ \\
\hline Proteína $(\%)$ & $3,2194^{\mathrm{a}}$ & $3,2065^{\mathrm{a}}$ \\
\hline Gordura $(\%)$ & $3,6548^{\mathrm{a}}$ & $3,7032^{\mathrm{a}}$ \\
\hline Lactose $(\%)$ & $4,5110^{\mathrm{a}}$ & $4,6071^{\mathrm{b}}$ \\
\hline
\end{tabular}

Letras distintas nas linhas representam diferenças estatísticas entre as médias $(\mathrm{P}<0,05) *$ Unidades Formadoras de Colônias.

\section{Conclusão}

Os resultados demonstraram que a análise de clusters hierárquicos é adequada para avaliação de práticas de manejo e higiene de ordenha. Além disso, que o Grupo 2, que realizou com maior frequência, práticas de manejo e higiene de ordenha, apresentou melhores resultados para qualidade do leite; diferenciando-se do Grupo 1 para as variáveis CBT e lactose.

\section{Referências}

BRASIL. Ministério da Agricultura, Pecuária e Abastecimento. Departamento de Inspeção de Produtos de Origem Animal. Instrução Normativa n 62, de 29 de dezembro de 2011. Aprova os regulamentos técnicos de produção, identidade e qualidade do leite. Diário Oficial [da] República Federativa do Brasil, Brasília, 30 dez. 2011. Seção I, p. 09. Disponível em: < http://central3.to.gov. br/arquivo/174314/>. Acesso em: 08 fev. 2014.

BUENO, V. F. F. et al. Contagem bacteriana total do leite: relação com a composição centesimal e período do ano no Estado de Goiás. Revista Brasileira de Ciência Veterinária, v. 15, p. 40-44, 2009.

CITADIN, A. S. et al. Qualidade microbiológica de leite cru refrigerado e fatores associados. Revista Brasileirade Saúde e Produção Animal, v. 10, p. 52-59, 2009.

CONFEDERAÇÃO da Agricultura e Pecuária do Brasil CNA. Valor bruto da produção - 2013. Disponível em: $<$ http://www.canaldoprodutor.com.br/>. Acesso em: 02 fev. 2014.

CUNHA, R. P. L. et al. Mastite subclínica e relação da contagem de células somáticas com número de lactações, produção e composição química. Arquivo Brasileiro de Medicina Veterinária e Zootecnia, v. 60, n. 1, p. 19-24, 2008.

ELMOSLEMANY, A. M. et al. The association between bulk tank milk analysis for raw milk quality and on farm management practices. PreventiveVeterinary Medicine, v. 95 , p. 32-40, 2010.

FAO. Food and Agriculture Organization. Statistical Database - Faostatis/Agriculture, 2014. Disponível em: $<$ http:// www.fao.org>. Acesso em: 03 fev. 2014.

FÁVERO, L. P. et al. Análise fatorial. In: FÁVERO, L. P. et al. Análise de dados: modelagem multivariada para tomada de decisões. Rio de janeiro: Elsevier, 2009.

FIGUEIREDO, A. P. G. et al. Qualidade do leite de propriedades da área de proteção ambiental da Bacia do Córrego da Velha no Município de Luz (MG). Ciência Equatorial, v. 2, n. 2, p. 35-53, 2012.

FONSECA, L. F. L.; SANTOS, M.V. Qualidade do leite e controle de mastite. São Paulo: Lemos, 2011. p. 151-161.

GONZÁLEZ, F. H.; DURR, J. W.; FONTANELLI, R. Uso do leite para monitorar a nutrição e o metabolismo de vacas leiteiras. Porto Alegre: UFGRS, p. 44-57, 2001. Disponível em: <http://www.ufrgs.br/lacvet/restrito/pdf/ leite\%20metabolismo.pdf.>. Acesso em: 14 fev. 2014.

LANGONI, H. et al. Aspectos microbiológicos e de qualidade do leite bovino. Pesquisa Veterinária Brasileira, v. 31, n. 12, p. 1059-1065, 2011.

LIMA, M. G. C. et al. Contagem de células somáticas e análises físico-químicas e microbiológicas do leite cru tipo c produzido na região agreste do estado de Pernambuco. Arquivos do Instituto Biológico, v. 73, n. 1, p. 89-95, 2006.

MACHADO, P. F.; PEREIRA, A. R.; SARRÍES, G. A. Composição do leite de tanques de rebanhos brasileiros distribuídos segundo sua contagem de células somáticas. Revista Brasileira de Zootecnia, v. 29, n. 6, p. 1883-1886, 2000 .

NERO, L. A.;VIÇOSA, G. N.; PEREIRA, F. E. Qualidade microbiológica do leite determinada por características de produção. Ciência e Tecnologia de Alimentos, v. 29, n. 2, p. 386-390, 2009.

PEDRICO, A. et al. Aspectos higiênico-sanitário na obtenção do leite no assentamento alegre no município de Araguaia-Tocantins. Ciência Animal Brasileira, v. 10, n. 2, p. 610-617, 2009.

RIBEIRO NETO, A. C. et al. Qualidade do leite cru refrigerado sob inspeção federal na região Nordeste. Arquivo Brasileiro de Medicina Veterinária e Zootecnia, v. 64, n. 5 , p. 1343-1351, 2012. 
ROSSI, A. P. et al. Milk composition and quality as a function of lactation phase and order. Revista Colombiana de Ciência Animal, v. 4, n. 1, p. 4-23, 2012.

SANTOS, M. V. dos et al. Remoção de células somáticas pela microfiltração não afeta a composição e a proteólise do leite. Ciência Rural, Santa Maria, v. 36, n. 5, p.1486-1493, 2006.

SILVA, L. C. C. et al. Rastreamento de fontes da contaminação microbiológica do leite cru durante a ordenha em propriedades leiteiras do Agreste Pernambucano.

Semina: Ciências Agrárias, v. 32, n. 1, p. 267-276, 2011.

UNITED STATES DEPARTMENT OF AGRICULTURE. Relatórios - Laticínios e Produtos. USDA, 2013.

Disponível em: < http://www.usdabrazil.org.br/home/>. Acesso em: 07 fev. 2014.

VALLIN, V. M. et al. Melhoria da qualidade do leite a partir da implantação de boas práticas de higiene na ordenha em 19 municípios da região central do Paraná. Semina: Ciências Agrárias, v. 30, n. 1, p. 181-188, 2009.

VIOTTO, W. H.; CUNHA, C. R. Teor de sólidos do leite e rendimento industrial. In: MESQUITA, A. J. et al. Perspectivas e avanços da qualidade do leite no Brasil. Goiânia: Talento, v.1, p. 241-258, 2006. Disponível em: $<$ http://cbql.com.br/biblioteca/cbq12/IICBQL241.pdf $>$. Acesso em: 18 fev. 2014.

YAMAZI, A. K. et al. Práticas de produção aplicadas no controle de contaminação microbiana na produção de leite cru. Bioscience Journal, v. 26, n. 4, p. 610-618, 2010. 